The author(s) shown below used Federal funds provided by the U.S. Department of Justice and prepared the following final report:

Document Title: The Course of Domestic Abuse among Chicago's Elderly: Risk Factors, Protective Behaviors, and Police Intervention, Executive Summary Report

Author:

Karen L. Amendola, PhD; Meghan G. Slipka, MA; Edwin E. Hamilton, MA, ABD, and Julie L. Whitman, MSW

Document No.: $\quad 232625$

Date Received: December 2010

Award Number: 2005-WG-BX-0012

This report has not been published by the U.S. Department of Justice. To provide better customer service, NCJRS has made this Federallyfunded grant final report available electronically in addition to traditional paper copies.

Opinions or points of view expressed are those of the author(s) and do not necessarily reflect the official position or policies of the U.S. Department of Justice. 


\title{
The Course of Domestic Abuse among Chicago's Elderly: Risk Factors, Protective Behaviors, and Police Intervention
}

\author{
Executive Summary Report
} submitted to

National Institute of Justice

by:

Karen L. Amendola, PhD; Meghan G. Slipka, MA; Edwin E. Hamilton, MA, ABD

Police Foundation

and

Julie L. Whitman, MSW

National Center for Victims of Crime

June 7, 2010 


\section{Acknowledgments}

First and foremost we would like to acknowledge Rob Davis, former Research Director at the Police Foundation, who, along with Michelle Webster of the National Center for Victims of Crime, designed this study and developed the measures. It is because of their commitment to the safety and well-being of senior citizens as well as their past efforts and knowledge in the areas of victimization and policing that this important work took place. Now with the Rand Corporation, Mr. Davis was instrumental in identifying and working with our partners -- the National Center for Victims of Crime and the Schaefer Center for Public Policy of the University of Baltimore (Schaefer Center).

The collection of victim information would not have been possible without the support of the Chicago Police Department, and especially former Deputy Superintendent Ellen Scrivner who paved the way for us to have access to the department and obtain necessary data. A number of people worked to ensure that we would be able to interview elderly victims. We especially would like to thank the staff of the Research and Development Division including Megan Alderden, Projects Administrator and particularly Timothy Lavery, Chief Operations Research Analyst who coordinated the efforts of the divisions and units of the CPD to obtain input, discuss procedures, and implement the project. Sergeant Kathy Argentino, supervisor of the Domestic Violence Office and Sergeant Cassandra Williams, supervisor of the Senior Citizen Services Section were instrumental in obtaining input from their officers about elderly victims, and providing ongoing project support. The former senior services sergeant, now Lieutenant Jeffrey Hoffman was instrumental in kicking off the project with Rob Davis.

We would like to extend our deep gratitude to Mary Lou Leary, former Director of the National Center for Victims of Crime and her staff including Michelle Webster, a co-author of the proposal, former staff member Michael Kaiser for his project coordination, Julie Whitman, MSW (co-author of this report), and Kerrin Darkow, Deputy Director of Victims' Services, all of whose knowledge and compassion for victims were at the heart of the project, providing input into the survey design efforts, as well as developing and administering training to interviewers from both the Schaefer Center and the Police Foundation.

We also wish to thank Don Haynes, Ph.D. of the Schaefer Center for spearheading the project on behalf of the Schaefer Center, and staff of the Schaefer Center including its director, Dr. Simon Bauer-Leffler and Williams Wells, Survey Research Coordinator who were responsible for overseeing the data collection and reporting efforts for the community sample.

The project was supported by a number of staff whom we would like to acknowledge for their project assistance including conducting interviews of victims. Among them are Research Associate Greg Jones, MA, and former staff Laura Wyckoff, MA; Kate Zinsser, BA, and our former fellow, Dr. LaTesha Watson, Sergeant in the Arlington, Texas Police Department. We greatly appreciate ongoing support provided by Professor David Weisburd, Chair of the Police Foundation's Research Advisory Committee who provided advice and counsel throughout. We also wish to acknowledge our President, Hubert Williams for his ongoing commitment to ensuring high quality research.

Finally, we would like to sincerely thank the National Institute of Justice and specifically Dr. Carrie Mulford our grant monitor for working so closely with us to ensure project success. It is their commitment to scientific research and the important issue of victimization of the elderly that made this research possible. 


\section{Background}

Elder abuse is a complex phenomenon that still lacks a single consistent definition (Anetzberger, 2005; Erlingsson, 2007). Since elder abuse was first discussed as a social problem in the mid-1970s, research into the prevention, detection, and understanding of victims and perpetrators has increased. Much of the research that has been conducted on elder abuse to date has been centered on prevalence, typology, and defining issues, including detection and risk indicators (Erlingsson, 2007). However, there still remain many issues that need to be examined in this field (Bonnie \& Wallace, 2003; Erlingsson, 2007). Other research has focused on the perpetrators; and the consensus is that most of the perpetrators are family members, and more specifically, often spouses of victims (Pillemer \& Finkelhor, 1988; and Davis, Medina, \& Avitabile, 2001).

Recently there have been two broad based national studies of elder abuse prevalence published in 2008 (Laumann, Leitsch, \& Waite) and 2009 (Acierno, Hernandez, Tejada, Muzzy, \& Steve). Acierno and colleagues attained higher prevalence estimates for physical and financial abuse attributing that to the inclusion of contextualizing statements in their survey instrument that "prime” respondents to include typically under-reported types of incidents, while Laumann’s study used only a single, non-contextualized item for each form of abuse.

A landmark 2003 National Research Council report identified a number of risk factors for elder abuse that had been substantiated by numerous studies (Bonnie \& Wallace, 2003). Some of the risk factors pertain to the victim while others pertain to the abuser, which have been suggested to be more predictive of abuse (Anetzberger, 2005).

There is limited research on the extent to which elderly victims use various services or engage in protective behaviors, nor their efficacy. And, while there has been research addressing 
the effectiveness of second responders or law enforcement officers who respond to incidents of intimate partner violence (see e.g. Davis, Maxwell, \& Taylor, 2006; Greenspan et al., 2004;

Pate, Hamilton, \& Annan, 1992; and Casey et al., 2007), there is a dearth of research examining such roles when dealing with elderly victims

\section{The Study}

In this study, we surveyed elderly residents from the city of Chicago. Our goal was to examine potential differences between those elderly residents who experienced at least one incident of domestic abuse (victims) and received a visit from a senior services officer (SSO) or domestic violence liaison officer (DVLO) from the Chicago Police Department (CPD) and those who did not. We also included a sample of elderly residents who had no incidents of abuse (nonvictims) in order to establish risk factors that differentiate victims from non-victims. Elderly was defined as those 60 years of age or more, consistent with the Chicago Police Department and Illinois Criminal Code definitions. Domestic abuse incidents were defined as incidents perpetrated by either a family member or member of the victim's household (i.e. someone who lives with the victim but is not a family member). In addition, we defined abuse to include physical, psychological, or financial abuse, and neglect. Our definitions of abuse were taken from previous victimization research (Brownell, 1998; Davis \& Webster, 2005; Wolf \& Pillemer, 1989).

Our study relied on examining two groups of elderly residents: 1) a statistically derived sample of all elderly residents in Chicago with phones, and 2) a convenience sample of elderly victims who were visited by a SSO or DVLO of the Chicago Police Department. Participants were interviewed twice separated by about ten months. Using the community-based sample, we 1) determined the prevalence rates for elder abuse in Chicago; and 2) established whether there 
were any differences in demographic characteristics and risk factors associated with victims and non-victims. Using the community and police samples, we 3) assessed the extent to which victim groups differed on various demographic characteristics, risk factors, and protective behaviors; 4) identified differences between the victim groups on the type and frequency of victimization; 5) analyzed subsequent victimization; 6) calculated the proportion of cases in which abuse increased, decreased, maintained, or desisted; and 7) examined whether there were any demographic characteristics, risk factors, and/or protective behaviors that predicted the course of abuse over time.

\section{Research Site and Methods}

We selected the City of Chicago as the site for our research primarily because of the Chicago Police Department's (CPD) heavy emphasis on elder abuse. Specifically, the CPD has an established Senior Citizens Services Section staffed by 25 SSOs and 25 DVLOs who respond to crimes against the elderly, and receive referrals from patrol officers, hotlines for the aging, and other provider agencies. These 50 officers also engage in prevention and outreach. The CPD provides an in-person mandatory follow-up with elderly victims of abuse by a SSO generally within two weeks of an incident to which police responded.

Phone interviews of community victims and non-victims were conducted by the Schaefer Center for Public Policy, University of Baltimore, Maryland (SCPP) and victims from the police sample by staff of the Police Foundation, Washington, DC. Our total sample size was 1,795 for which we established that there were 1,603 non-victims, 153 victims, and 39 for whom victimization status could not be established.

A sampling strategy using a databank of phone numbers in the City of Chicago was used to obtain the community sample (victims and non-victims). In order to obtain our sample of 
victims from the police department, SSOs and DVLOs who made a contact with an elder abuse victim, provided a brief description of the phone survey and provided the victim with a volunteer form in which he/she would indicate his/her willingness to be contacted and the forms were returned to us to make contact with the willing victims.

Prior to beginning data collection, we conducted training sessions with the Senior Citizen Services Section and Domestic Violence Office, along with staff from the Research and Development Division of the CPD. Training was also provided to all interviewers by the staff of the National Center for Victims of Crime.

We conducted interviews with a total of 121 victims in the community sample, 48 victims in the police sample, and 159 non-victims in the community sample. While our sample size was larger for the community groups, our response rate and cooperation rate was higher for the police sample, and the refusal rate and attrition were both lower in the police sample. The study’s power was sufficient for detecting medium effect sizes or larger, though insufficient for detecting small effect sizes.

\section{Measures}

In order to address our research questions, we examined existing measures from a variety of sources (primarily Pillemer, 1985; Bowker, 1984), and used those to develop two surveys: one for victims and the other for non- victims. The final surveys by Davis and Webster (2005) had questions about types of abuse (physical, psychological, financial, and neglect); dependency status of participants (dependence of the abuser on the victim and vice-versa); and questions about service use or other protective behaviors. We used a standardized screener to assess cognitive capacity/dementia (Callahan, Unverzagt, Hui, Perkins, \& Hendrie, 2002), and four broad abuse screening questions. 


\section{Findings}

Prevalence rates for our sample were similar to those found in other studies of elder abuse. For financial abuse/exploitation, we attained a prevalence rate of $2.28 \%$. For psychological/emotional abuse our rate of prevalence was $4.61 \%$. We obtained a prevalence rate for physical abuse of less than $1 \%$ and for neglect, it was $1.37 \%$. Using a $95 \%$ confidence interval, all of the ranges were reasonably small.

Our findings suggest a number of risk factors for abuse among our community sample participants, many of which are consistent with past research. First, victims and non-victims differ with regard to race and household size. Specifically, Blacks were more likely to be elder abuse victims than were whites. This finding is consistent with other studies that have found racial differences in victimization (Tatara, 1999; Laumann, et al., 2008), and past data generated by the Chicago Police Department (2005). In addition, victims were significantly more likely to live with two or more people than were the non-victims, and non-victims were much more likely to live alone, consistent with Lachs, et al. (1996).

Victims were significantly more likely to need assistance from their abuser in having their rent, groceries, or medicines paid; providing personal care; and assisting with daily activities than were non-victims’ primary significant others (PSOs). Abusers were significantly more likely to be either entirely or somewhat dependent on their victims for a place to live; having groceries or expenses paid; cooking and cleaning; and for other daily responsibilities, than were the PSOs of the non-victims, consistent with past findings (Pillemer \& Finkelhor, 1989; Wolf \& Pillemer, 1989).

There were a number of characteristics that differentiate abusers from non-abusive PSOs. First, victims were more likely to report that their abusers had engaged in deviant behaviors in 
the past (destroyed other's property, been violent towards others, or been arrested) as compared to non-victims’ PSOs. This is not surprising given that previous work by Lachs \& Pillemer (1995) suggested that violence toward others was an abuser risk factor. In addition, victims were much more likely to report that their abusers had emotional problems, been hospitalized for psychiatric reasons, and both drinking and drug problems, compared to non-victims’ PSOs. These findings too, confirm past research on mental illness and elder abuse (e.g. Acierno, et al., 2009; Godkin, Wolf, \& Pillemer, 1989; Wolf \& Pillemer, 1989). Similarly, substance abuse by perpetrators has been shown to be associated with elder abuse in other studies (e.g. Acierno, et. al., 2009; Reay \& Browne, 2001). In addition, abusers were more likely to have serious stress factors in the past year such as job loss, re-location, serious illness, and death of a member of their household compared to those of non-victims' PSOs, findings that are consistent with those of Godkin and colleagues (1989). However, this contradicts the assertion by Acierno, et al. (2009) that caregiver stress does not appear to be associated with likelihood of perpetration, although they suggest that caregiver stress may affect the intensity of the abuse.

\section{Risk Factors Differentiating Victims in the Community and Police Samples}

In comparing characteristics of victims in both sample groups, there were a number of differences. First, while females had a higher rate of victimization in both groups, males made up a higher proportion of those in the police sample, suggesting that they may be more willing to contact the police when they are being 'pushed around,' as compared to females, although we don't know how many of the victims in the police sample had themselves contacted the police. While Blacks were disproportionately represented in both samples, they were significantly more likely to be in the police sample than were whites. This is certainly likely to be due to the fact that Black victims are more likely to report violence to the police (Felson, Messner, \& Hoskin, 
1999; Hart \& Rennison, 2003; Rennison, 1999). Victims from the police sample were more likely to report that the perpetrators were non-family household members, or other more distant family members compared to community victims who were more likely to be abused by immediate family members. This may suggest that family members may be less willing to get police involved when their abuse is at the hands of a close relative. Victims in the police sample were more likely to report that their abusers depended on them for a place to live and to have their groceries and expenses paid by the victim. The fact that abuser dependency was greater for those in the police sample may be due to victims' unwillingness to throw out a dependent abuser, and instead resort to police assistance.

Victim respondents from the police sample were significantly more likely to indicate that their abuser had a history of violence towards others, been arrested in the past, emotional problems, been hospitalized for psychiatric disorders, or drinking problems than those victims in the community sample. This may be due to the fact that psychiatric, alcohol, and drug problems are often associated with deviant or illegal behaviors (see e.g. Murdoch \& Ross, 1990; Hodgins \& Müller-Isberner, 2004; Boles \& Miotto, 2003), thereby requiring greater police intervention.

\section{Abuse Types and Frequency Across Victim Samples}

We examined victimization as reported by the broad categories of abuse and found no differences between the sample groups with regard to financial abuse, neglect, or emotional abuse (as assessed by the abuse screener). However, victims in the police sample were much more likely to have reported being physically abused which is not surprising given that physical abuse is more likely to require or result in police involvement. The fact that the screener did not detect sample group differences for the other three types of abuse, suggests the lack of sensitivity 
of the screener, as suggested by Acierno and colleagues (2009) who asserted that when more context specific questions about abuse are used, the level of reported abuse increases.

When using context-specific items to assess abuse, there were considerable differences across a number of forms of abuse. First, victims from the police sample were significantly more likely to have experienced a number of forms of emotional abuse such as having a household member insult or swear at them; threaten to lock them out of the house; restrict their use of the telephone; or threaten to hit or throw something. With regard to financial abuse, victims from the police sample were significantly more likely to have had the abuser destroy their property. ${ }^{1}$ Similarly, with regard to physical violence, those in the police sample were more likely to have reported that a household member had thrown something at them; pushed, grabbed or shoved them; slapped them; threatened them with a weapon; injured them with a knife; kicked, bit, or hit them with a fist; beat them up; or threatened to kill or hurt them. However, in Time 2, these differences were not present suggesting that the police intervention may have had an impact upon reducing the proportion of cases of subsequent victimization.

Poly-victimization. Victims in the police sample were also significantly more likely to have experienced multiple forms of abuse (poly-victimization) at the time of the initial interviews. Yet, this effect was not present in Time 2, suggesting the efficacy of the police intervention in reducing the proportion of those with poly-victimization. This trend should be further explored in subsequent research.

Frequently occurring forms of abuse. Finally, while there was a significantly greater likelihood of at least one subsequent abuse incident for those in the police sample, the number of forms of abuse that occurred frequently ( $>10$ times) went down significantly for the victims in

\footnotetext{
${ }^{1}$ Because the financial abuse scale was not reliable, it is not certain whether destruction of property is actually a form of financial abuse or instead may represent a form of emotional abuse.
} 
the police sample from about 6 forms of frequently occurring abuse to just over 2, suggesting that the police intervention by officers specially trained to deal with domestic abuse and/or elder abuse was efficacious.

\section{Sample Group Differences in Protective and Service-Seeking Behaviors.}

When controlling for demographic variables such as sex, race, and household size, victims in the police sample were significantly more likely to have engaged in protective behaviors and support seeking, than were those in the community sample. However, a greater proportion of those in the community sample reported having sought help from the police than did those in the police sample. This is probably due to the fact that victims in the police sample had received a visit from a specially trained officer prior to our initial interview, so they did not need to contact the police again. The findings suggest that the SSOs or DVLOs may have been instrumental in encouraging victims to use available resources even if they had not called the police themselves. Additionally, the proportion of victims in the police sample who engaged in protective and service-seeking behaviors went up in Time 2, including for seeking help from the police. This may mean that the victims in the police sample were confident with the contact they had with the police initially and were more likely to contact them in the future. Besides seeking help from the police, the only other behavior that Time 1 victims in the community sample were more likely to engage in than those in the police sample was talking with friends or family about abuse. It seems then, that victims in the community sample resort to seeking social support as opposed to more formal means for protecting themselves or getting various support services.

The findings overall seem to suggest that the referrals and/or other information received in their initial contact with the SSOs or DVLOs were helpful to victims providing resources and guidance about what types of support they could seek to prevent, reduce, or stop subsequent 
abuse. And it also appears that these protective and service seeking behaviors may have influenced the abusive outcomes. Since this study represents the first known data collection effort related to the role of police in elder abuse, more rigorous follow-up studies are necessary to confirm the differences found between victims who were visited by officers specially trained to deal with domestic abuse and/or elder abuse and those who were not.

\section{Limitations of the Present Study}

This study had a number of limitations including: 1) oversampling in areas within Chicago that had higher proportions of elderly (via census blocks); 2) under-representation of Hispanics and Asians, and over-representation of Blacks; 3) not conducting interviews in Spanish; 4) using an abuse screener that was not highly sensitive; 5) using measures that lacked historical evidence of reliability and validity data; 6) conducting interviews by phone; 7) excluding sexual abuse; 8) only considering domestic abuse of the elderly and not abuse perpetrated by others; and 9) conducting the study in just one site with specific and unique characteristics.

\section{Implications}

The results of this study suggest the need for future research in examining the role of police in intervention with elder abuse victims. Indeed using a multivariate regression model, we found that those victims who received a visit by a specially trained officer, were more likely to have engaged in service seeking and protective measures than those who did not. Victims in the police sample were more likely to have experienced a range of abusive types and behaviors, including poly-victimization in the first interview, but by the follow-up interview, these differences were no longer evident, suggesting that the visits by specially trained officers were efficacious in reducing the proportions of police victims. Additionally, when examining the 
course of abuse for those in the police sample, the number of frequently occurring ( $>10$ times in the past year) forms of abuse were reduced from about six to around 3.5, suggesting the police contact was efficacious. This certainly has implications for police agencies that are considering establishing elder abuse units or providing specialized training for their officers in domestic abuse of the elderly. Although this is the first exploratory study focused on the role of the police in elder abuse, future research using more rigorous designs would allow for more conclusive and comprehensive results. 


\section{References}

Acierno, R., Hernandez-Tejada, M., Muzzy, W., \& Steve, K. (2009). National Elder Mistreatment Study. Washington, DC: National Institute of Justice.

Anetzberger, G. (2005). The reality of elder abuse. Clinical Gerontologist, 28, 1-25. doi: 10.1300/J018v28n01_10

Boles, S.M., \& Miotto, K. (2003). Substance abuse and violence: A review of the literature. Aggression and Violent Behavior, 8(2), 155-174. doi: 10.1016/S1359_1789(01)00057-X

Bonnie, R.J., \& Wallace, R.B. (2003). Elder Mistreatment: Abuse, Neglect, and Exploitation in an Aging America. Washington, DC: The National Academies Press, National Research Council.

Bowker, L.H. (1984). Battered wives and the police: A national study of usage and effectiveness. Police Studies, 7, 84-93. Retrieved from: http://www.ncjrs.gov/App/Publications/ abstract.aspx?ID=94637

Brownell, P. J. (1998). Family Crimes Against the Elderly: Elder Abuse and the Criminal Justice System. London: Routledge

Callahan, C.M., Unverzagt, F.W., Hui, S.L., Perkins, A.J., \& Hendrie, H.C. (2002). Six item screener to identify cognitive impairment among potential subjects for clinical research. Medical Care, 40(9), 777-781. doi: 10.1097/01.MLR.0000024610.33213.C8

Casey, R.L., Berkman, M., Stover, C.S., Gill, K., Durso, S., \& Marans, S. (2007). Preliminary results of a police-advocate home-visit intervention project for victims of domestic violence. Journal of Psychological Trauma, 61, 39-49. Retrieved from: http://www.ncjrs.gov/App/Publications/ abstract.aspx?ID=242719

Davis, R.C., Maxwell, C., \& Taylor, B. (2006). Preventing repeat incidents of family violence: Analysis of data from three field experiments. Journal of Experimental Criminology, 2, 183210. doi: 10.1007/s11292-006-9002-0

Davis, R.C., Medina, J., \& Avitabile, N. (2001). Reducing Repeat Incidents of Elder Abuse: Results of a Randomized Experiment. Washington, DC: National Institute of Justice. Retrieved from: http://www.ncjrs.gov/pdffiles1/nij/grants/189086.pdf

Davis, R.C., \& Webster, M. (2005). Elder abuse: Risk factors, the course of abuse over time, and the effect of protective measures on repeat rates. A proposal submitted to the National Institute of Justice. Washington, DC: National Institute of Justice.

Felson, R.B., Messner, S.F., \& Hoskin, A. (1999). The victim-offender relationship and calling the police in assaults. Criminology, 37(4), 901-917. 
Godkin, M.A., Wolf, R.S., \& Pillemer, K.A. (1989). A case comparison analysis of elder abuse and neglect. International Journal of Aging and Human Development, 28, 207-225.

Greenspan, R., Weisburd, D., Lane, E., Ready, J., Crossen-Powell, S., \& Booth, W.C. (2003). The Richmond/Police Foundation domestic violence partnership. Washington, DC: Police Foundation.

Hart, T.C. \& Rennison, C. (2003). Reporting Crime to the Police: 1992-2000. Washington, DC: Bureau of Justice Statistics.

Hodgins, S., \& Müller-Isberner, R. (2004). Preventing crime by people with schizophrenic disorders: The role of psychiatric services. The British Journal of Psychiatry, 185, 245250.

Lachs, M.S., \& Pillemer, K. (1995). Abuse and neglect of elderly persons. New England Journal of Medicine, 332, 437-443. Retrieved from: http://content.nejm.org/cgi/content/ extract/332/7/437

Lachs, M.S., Williams, C., O’Brien, S., Hurst, L., \& Horwitz, R. (1996). Older adults: An 11year longitudinal study of adult protective service use. Archives of Internal Medicine, 156(4), 449-453. Retrieved from http://www.ncbi.nlm.nih.gov/pubmed/8607731

Laumann, E.O., Leitsch, S.A., \& Waite, L.J. (2008). Elder mistreatment in the United States: Prevalence estimates from a nationally representative study. The Journals of Gerontology Series B: Psychological Sciences \& Social Sciences, 63, S248-S254. Retrieved from: http://psychsoc.gerontologyjournals.org/cgi/reprint/63/4/S248

Murdoch, D., \& Ross, D. (1990). Alcohol and crimes of violence: Present issues. Substance use \& misuse, 25(9), 1065-1081. doi: 10.3109/10826089009058873

Pate, A., Hamilton, E.E., \& Annan, S. (1992). Metro-Dade spouse abuse replication project technical report. Washington, D.C.: Police Foundation.

Pillemer, K. (1985). The dangers of dependency: New findings on domestic violence against the elderly. Social Problems, 33(2), 146-158. Retrieved from: http://www.jstor.org/stable/ 800558

Pillemer, K., \& Finkelhor, D. (1988). The prevalence of elder abuse: A random sample survey. The Gerontologist, 28(1), 51-57. Retrieved from: http://gerontologist.oxfordjournals.org/ cgi/reprint/28/1/51

Pillemer, K., \& Finkelhor, D. (1989). Cause of elder abuse: Caregivers stress versus problem relatives. American Journal of Orthopsychiatry, 59(2), 179-187. Retrieved from: http://www.ncbi.nlm.nih.gov/pubmed/2712152 
Reay, A.M., \& Browne, K.D. (2001). Risk factors for caregivers who physically abuse or neglect their elderly dependents. Aging \& Mental Health, 5(1), 56-65. doi: $10.1080 / 13607860020020654$

Tatara, T. (1999). Introduction. In T. Tatara (Ed.), Understanding elder abuse in minority populations (1-9). Washington, DC: Taylor and Francis.

Wolf, R.S., \& Pillemer, K. (1989). Helping Elderly Victims: The Reality of Elder Abuse. New York, NY: Columbia University Press. 